\title{
Studies of Cooling Effects of Sprinkler Spray on Smoke Layer
}

\author{
S.C. $\mathrm{Li}^{1,2}$, D. Yang ${ }^{1}$, R. Huo ${ }^{1 *}$, L.H. Hü ${ }^{1 *}$ Y.Z. Li ${ }^{1}$, K.Y. Li ${ }^{1}$ and H.B. Wang ${ }^{1}$
}

1. State Key Laboratory of Fire Science

University of Science and Technology of China, Hefei 230027, China

2. Department of Fire Command

The Chinese People's Armed Police Force Academy

Langfang 065000, China

*Corresponding author: Tel: (86) 551 3601660; Fax: (86) 551 3601669; Email address:

huoran@ustc.edu.cn; hlh@ustc.edu.cn

Postal address: State Key Laboratory of Fire Science, University of Science and Technology of

China, Hefei, Anhui, 230026, China

\begin{abstract}
An experimental study was performed to measure the cooling of a smoke layer by water sprays. This was followed by the development of a mathematical model based on the theory of Chow and Tang. The predictions of the model agree well with the experimental measurements. Water sprays investigated in the present work provided significant cooling of the smoke layer. We observed little effect of increasing the water pressure from 50 to $100 \mathrm{kPa}$ on the cooling of the smoke layer.
\end{abstract}

KEYWORDS: Sprinkler spray; smoke layer; heat transfer; sprinkler cooling

\section{NOMENCLATURE LISTING}

\begin{tabular}{|c|c|c|c|}
\hline$c$ & sprinkler flow coefficient & $S(i)$ & surface area of droplet of diameter $i\left(\mathrm{~m}^{2}\right)$ \\
\hline$c_{p}$ & $\begin{array}{l}\text { specific heat of water } \\
(\mathrm{kJ} / \mathrm{kg} \cdot \mathrm{K})\end{array}$ & $T$ & temperature of smoke $(\mathrm{K})$ \\
\hline$C_{p s}$ & $\begin{array}{l}\text { specific heat of smoke } \\
(\mathrm{kJ} / \mathrm{kg} \cdot \mathrm{K})\end{array}$ & $T(i)_{w}$ & temperature of droplet of diameter $i(\mathrm{~K})$ \\
\hline$C_{p s 2}$ & $\begin{array}{c}\text { specific heat of the smoke } \\
\text { after sprinkler operation } \\
(\mathrm{kJ} / \mathrm{kg} \cdot \mathrm{K})\end{array}$ & $u$ & velocity of hot smoke $(\mathrm{m} / \mathrm{s})$ \\
\hline$C_{d}$ & resistance coefficient & $u_{0}$ & $\begin{array}{l}\text { initial horizontal component of droplet velocity } \\
\qquad(\mathrm{m} / \mathrm{s})\end{array}$ \\
\hline$C_{m}$ & sprinkler diameter coefficient & $U$ & droplet velocity $(\mathrm{m} / \mathrm{s})$ \\
\hline$d_{m}$ & $\begin{array}{l}\text { average volume diameter of } \\
\text { droplets }(\mu \mathrm{m})\end{array}$ & $U_{s}$ & smoke velocity $(\mathrm{m} / \mathrm{s})$ \\
\hline$d_{n}$ & nozzle inner diameter $(\mu \mathrm{m})$ & $v$ & droplet vertical velocity $(\mathrm{m} / \mathrm{s})$ \\
\hline$h$ & $\begin{array}{l}\text { heat transfer coefficient } \\
\qquad\left(\mathrm{W} / \mathrm{m}^{2} \cdot \mathrm{k}\right)\end{array}$ & $v_{0}$ & initial vertical velocity of droplet $(\mathrm{m} / \mathrm{s})$ \\
\hline$h(i)$ & $\begin{array}{l}\text { heat transfer coefficient of } \\
\text { droplet of diameter } i \\
\left(\mathrm{~kW} / \mathrm{m}^{2} \cdot \mathrm{K}\right)\end{array}$ & V & sprinkler flow rate $\left(\mathrm{m}^{3} / \mathrm{s}\right)$ \\
\hline$i$ & droplet diameter $(\mu \mathrm{m})$ & $W$ & width of sprinkler chamber $(\mathrm{m})$ \\
\hline$k$ & $\begin{array}{l}\text { coefficient of thermal } \\
\text { conductivity }(\mathrm{W} / \mathrm{m} \cdot \mathrm{K})\end{array}$ & $h$ & elevation of smoke layer above ground (m) \\
\hline$K$ & resistance term & $H$ & height of sprinkler chamber (m) \\
\hline$m$ & mass of water droplet $(\mathrm{kg})$ & $T_{f}$ & $\begin{array}{l}\text { temperature of droplet that reaches the bottom } \\
\text { of the smoke layer }(\mathrm{K})\end{array}$ \\
\hline$m_{p}$ & $\begin{array}{l}\text { mass production rate of } \\
\text { smoke }(\mathrm{kg} / \mathrm{s})\end{array}$ & $\Delta T$ & $\begin{array}{l}\text { temperature difference between smoke and } \\
\text { ambient air }(\mathrm{K})\end{array}$ \\
\hline$n(i$ & mass of droplet of diameter $i$ & $\Delta T_{2}$ & $\begin{array}{l}\text { temperature difference between smoke and } \\
\text { ambient air after sprinkler operation }(\mathrm{K})\end{array}$ \\
\hline$J(i)$ & number of droplets of & $y(i)$ & probability of droplet of diameter $i$ in log- \\
\hline
\end{tabular}




\begin{tabular}{|c|c|c|c|}
\hline$N u(i)$ & $\begin{array}{c}\text { diameter } i \\
\text { Nusselt number of droplet of } \\
\text { diameter } i\end{array}$ & & normal distribution \\
\hline$P$ & sprinkler pressure (MPa) & & Greek \\
\hline $\operatorname{Pr}$ & Prandtl number of air & $\delta$ & $\begin{array}{c}\text { parameter in log-normal distribution of droplet } \\
\text { sizes }\end{array}$ \\
\hline$Q$ & $\begin{array}{l}\text { experimental value of } \\
\text { sprinkler cooling }(\mathrm{kW})\end{array}$ & $\alpha$ & empirical coefficient \\
\hline$Q_{1}$ & $\begin{array}{l}\text { energy of smoke before } \\
\text { sprinkler operation }(\mathrm{kW})\end{array}$ & $\rho_{s}$ & density of smoke $\left(\mathrm{kg} / \mathrm{m}^{3}\right)$ \\
\hline$Q_{2}$ & $\begin{array}{l}\text { energy of smoke after } \\
\text { sprinkler operation }(\mathrm{kW})\end{array}$ & $\rho_{w}$ & density of water $\left(\mathrm{kg} / \mathrm{m}^{3}\right)$ \\
\hline$Q_{c}$ & convective heat transfer $(\mathrm{kW})$ & $\sigma_{w}$ & surface tension of water $(\mathrm{N} / \mathrm{m})$ \\
\hline$Q_{c x}$ & $\begin{array}{l}\text { actual heat removed by spray } \\
\qquad(\mathrm{kW})\end{array}$ & $\eta$ & $\begin{array}{l}\text { fraction of droplets not removed by } \\
\text { obstructions }\end{array}$ \\
\hline $\begin{array}{c}\operatorname{Re}(i) \\
S\end{array}$ & $\begin{array}{l}\text { Reynolds number of droplet } \\
\text { of diameter } i \\
\text { smoke circulation area }\left(\mathrm{m}^{2}\right)\end{array}$ & $v$ & smoke kinematic viscosity $\left(\mathrm{m}^{2} / \mathrm{s}\right)$ \\
\hline
\end{tabular}

\section{INTRODUCTION}

Automatic fire sprinkler systems are increasingly used in fire protection applications. Normally, sprinklers are installed at the ceiling. When the temperature at a sprinkler head reaches a predetermined value, the thermal element in the sprinkler activates and the water discharges from a pipe. Sprinklers control fires by four mechanisms: (1) they cool down the surface of the combustible materials; (2) they wet the surrounding material and reduce the flame spread; (3) they displace air with water vapor due to evaporation; and (4) they cool hot smoke layer and reduce its radiation $[1,2]$.

A number of studies have been performed to investigate the effects of sprinklers on the smoke produced by a fire [3-6]. Morgan [3, 4] analyzed the heat transfer between water droplets and a hot smoke layer, using a simple model. More recent work was reported by Cooper [5, 6]. Cooper focused on the behavior of the smoke layer under sprinkler spray, and developed a physical model. Studies involving numerical modeling were later conducted by Alpert [7], Hoffmann [8], Gardiner [9] and Chow [10-12].

Chow and Tang [13] also studied the heat transfer between the sprinkler spray and hot smoke layer, both theoretically and experimentally. Temperatures at different points in smoke layer were measured, but the study was not extended to predicting the heat transfer between the smoke layer and the sprinkler spray. Their model needs further full scale validations.

Starting from the theoretical analysis of Chow and Tang, in this contribution, we develop a new model for heat transfer between the hot layer and water spray. We also perform full scale experiments to validate the model.

\section{MATHEMATICAL MODEL}

\section{Characterization of the sprinkler spray droplets properties}

Water is ejected from the sprinkler orifice and impacts onto the deflector to form a spray. We employ the log-normal distribution to characterize the droplet sizes [14]:

$y(i)=\frac{1}{i \delta \sqrt{2 \pi}} \exp \left\{\frac{-\left[\ln \left(\frac{i}{d_{m}}\right)\right]^{2}}{2 \delta^{2}}\right\}$ 
where $y(i)$ is droplet-size distribution function, $i$ the droplet diameter, $d_{m}$ average volume diameter of droplet, $\delta$ the deviation of the function, with the value of $0.56 \leq \delta \leq 0.78$.

The volume medium diameter of the sprinkler spray droplets is taken as [15]:

$d_{m}=C_{m} W e^{-\left(\frac{1}{3}\right)} d_{n}$

where $d_{n}$ is inner diameter of the nozzle, We Weber number, with the coefficient $C_{m}$ taken as 2.33 for ZSTP-15 sprinkler [16,17].

The Weber number is defined as:

$W e=\frac{\rho_{w} U^{2} d_{n}}{\sigma_{w}}$

where $U$ is the drop velocity, $\sigma_{w}$ the surface tension of water equal to $72.8 \mathrm{mN} / \mathrm{m}$.

Droplet velocity is taken as:

$U=\frac{V}{\pi d_{n}{ }^{2} / 4}$

where $V$ is the flow rate of sprinkler.

The flow rate of sprinkler can be calculated by:

$V=\frac{c \sqrt{10 P}}{60000}$

where $c$ is the sprinkler flow coefficient, with a constant value of 80 for ZSTP-15 sprinkler, and $P$ denotes sprinkler pressure.

The number of droplets with different diameters can be calculated by the following equation [3]:

$N(i)=\frac{V \times y(i)}{\sum_{i=1}^{N} \frac{y(i)}{6} \times \pi \times i^{3}}$

where $N(i)$ is the number of droplets whose diameter is $i$.

For a single droplet, in accordance with Newton's second law, Bullen [18] presented an equation for the droplet vertical velocity as: 
$m g-K v^{2}=m \frac{d v}{d t}=m v \frac{d v}{d x}$

where $m$ is the mass of a water droplet, $K$ is resistance term, and $v$ corresponds to the droplet vertical velocity.

By solving equation (7), one obtains the droplet vertical velocity as a function of height:

$v^{2}=\frac{m g}{K}+\left(v_{0}^{2}-\frac{m g}{K}\right) e^{-\frac{2 K x}{m}}$

where $v_{0}$ is the droplet initial velocity.

Initial horizontal velocity of sprinkler droplets is:

$u_{0}=\alpha U$

where $u_{0}$ is initial horizontal velocity component, $\alpha$ is an empirical coefficient which is taken to be 0.4 .

Initial droplet vertical velocity corresponds to:

$v_{0}=\sqrt{U^{2}-u_{0}^{2}}$

Resistance term can be expressed by equation:

$K=\frac{1}{8} \rho_{a} C_{d} \pi \mathrm{i}^{2}$

where $\rho_{a}$ is the density of air, and $C_{d}$ is drag coefficient.

$C_{d}$ is obtained from

$$
\begin{aligned}
& \mathrm{C}_{\mathrm{d}}=24 \mathrm{Re}^{1 / 2} \quad \operatorname{Re}<1 \\
& 0.6 \quad 1 \leq \operatorname{Re}<1 \times 10^{3} \\
& 0.47 \quad 1 \times 10^{3} \leq \operatorname{Re}<3 \times 10^{5} \\
& 0.2 \quad 3 \times 10^{5} \leq \mathrm{Re}
\end{aligned}
$$

The Reynolds number of a droplet can be expressed as:

$$
\operatorname{Re}(i)=\frac{u i}{v}
$$


where $\operatorname{Re}(i)$ is Reynolds number of a droplet of diameter $i, u$ is the velocity of hot smoke, and $v$ is the kinematic viscosity of the smoke.

The Nusselt number of a sprinkler droplet of diameter $i$ is

$N u(i)=2+\left(0.4 \operatorname{Re}(i)^{0.5}+0.06 \operatorname{Re}(i)^{2 / 3}\right) \operatorname{Pr}^{0.4}$

$\operatorname{Pr}$ is the Prandtl number of the air which is taken to be 0.7 .

The Nusselt number can also be expressed as:

$N u(i)=\frac{h(i) i}{k}$

where $h(i)$ is convective heat transfer coefficient of the droplet whose diameter is $i, k$ is coefficient of thermal conductivity of the air.

Equation(14) can also be expressed as:

$h(i)=\frac{N u(i) \times k}{i}$

\section{Heat transfer between droplets and smoke}

For a fraction of droplets of diameter $i$, the energy conservation equation corresponds to [13]:

$m(i) C_{p} \frac{d T(i)_{w}}{d t}=h(i) S(i)\left(T-T(i)_{w}\right)$

where $m(i)$ is the mass fraction of droplets of diameter $i, T(i)_{w}$ the temperature of droplets of diameter $i, S(i)$ surface area of droplets of diameter $i$, and $T$ the temperature of the smoke layer.

Equation 16 can be rewritten as:

$\frac{4}{3} \pi\left(\frac{i}{2}\right)^{3} \rho_{w} v C_{p} \frac{d T(i)_{w}}{d x}=\frac{k N u(i)}{i} \pi i^{2}\left(T-T(i)_{w}\right) \quad\left(T(i)_{w} \leq 373 K\right)$

in Eq. 17, the $x$ denotes vertically downward direction. The evolution of the temperature of a sprinkler droplet can be calculated by solving the above equation using the Runge/Kutta method.

When the temperature of a smoke layer is high, small droplets easily reach a boiling point temperature. However, in our experiments, the thickness and the temperature of the smoke layer allow only a small fraction of water droplets to reach the boiling point. For this reason, the model neglects the evaporative cooling.

The heat absorbed by a droplet of diameter $i$ is 
$Q_{c}(i)=m(i) c_{p}\left(T_{f}-T_{0}\right) N(i) \quad\left(T_{f} \leq 373 K\right)$

where $T_{f}$ corresponds to the temperature of the droplet that reach the bottom of the smoke layer. Equation 18 restricts the droplet temperature to below the boiling point. Although it is possible that very small droplets can start to boil during their passage through the smoke layer, the mass fraction of such droplets is small.

The total heat transferred from the smoke layer to spray droplets equals:

$Q_{c}=\sum_{i=1}^{N} \frac{4}{3} \pi\left(\frac{i}{2}\right)^{3} \rho_{w} C_{p}\left(T_{f}-T_{0}\right) N(i)$

where $Q_{c}$ is convective heat transfer, $\rho_{w}$ is the density of water, $C_{p}$ is the specific heat of water.

Combining Eqs. 1, 6, 8, 15, 17-19, we can calculate the heat absorbed by water droplets that pass through smoke layer characterized by given temperature and thickness.

The above calculation of the spray cooling assumes no removal of droplets by obstructions; i.e., all droplets traverse the entire smoke layer and. However, in practice, sprinklers may be located in corridors, lobbies, where substantial number of droplets are removed from the spray by collisions with walls, and do not participate in the heat exchange with the smoke layer. Therefore, the value of spray cooling calculated above needs be modified as:

$Q_{c x}=\eta Q_{c}$

where $Q_{c x}$ denotes the actual heat removed by the spray, $\eta$ is the fraction of droplets able to penetrate the smoke layer; i.e., the droplets that are not removed by obstructions. Since the area of the spray chamber is 8 $\mathrm{m}^{2}$, and the the sprinkler coverage corresponds to $20 \mathrm{~m}^{2}$ [19], we estimate the value of the parameter $\eta$ to be 0.4 .

\section{EXPERIMENTS}

The experimental apparatus is shown in Fig. 1. It consists of the connected combustion and sprinkler chambers. As shown in Fig. 1, pool fires were burned in the combustion chamber to generate an initial stable smoke layer in the upper region of the sprinkler chamber. The combustion chamber was $2.5 \mathrm{~m}$ in length, $1.22 \mathrm{~m}$ in width and $2.2 \mathrm{~m}$ in height. The opening between the combustion and sprinkler chamber was $1.22 \mathrm{~m}$ in width and $1.8 \mathrm{~m}$ in height. The dimensions of the sprinkler chamber corresponded to 4 (length) $\times 2$ (width) $\times 2.6$ (height) $\mathrm{m}$. In order to ensure adequate air supply, the combustion and sprinkler chambers were equipped with vents at the bottom and side walls, as illustrated in Fig. 1. A smoke curtain with height of $2.2 \mathrm{~m}$ was installed below the ceiling of the sprinkler chamber to form a smoke layer of $1 \mathrm{~m}$ in initial thickness.

A single sprinkler was installed at the center point of the ceiling of the sprinkler chamber. Two thermocouples trees, each with 12 thermocouples, were located symmetrically $1 \mathrm{~m}$ away from the sprinkler. We used K-type thermocouples, $0.3 \mathrm{~mm}$ in diameter, and accurate to $\pm 1^{\circ} \mathrm{C}$. The vertical interval between the thermocouples was $0.15 \mathrm{~m}$. In order to minimize the cooling of the thermocouple by the water spray, a 
thin reverse "U" shaped metal shield was installed above the thermocouples. These metal shields prevented water from the sprinkler reaching the thermocouples directly. The dimensions of the thermocouples trees are shown in Fig. 1.

ZSTP-15 sprinkler with the nozzle diameter of $12.7 \mathrm{~mm}$ was used for all experiments. A pressure reducing valve and a pressure transmitter were installed on the water pipe to control the operating pressure of the sprinkler with an accuracy of $0.002 \mathrm{MPa}$.

In total 16 tests were conducted with the smoke layer generated by diesel (heat of combustion of $42 \mathrm{MJ} / \mathrm{kg}$ ) pool fires of four sizes. The transient mass of the fuel was measured by a weighting system with six strain gauges, capable of measuring mass of up to $60 \mathrm{~kg}$. The heat release rates of the pool fires were calculated from the mass loss rates of the fuel with the combustion efficiency assumed to be $75 \%$ of that calculated from the heat of combustion. Table 1 summarized the heat release rates for all experiments. The sprinkler spray was discharged at the same time after the ignition. The total burning time of each test was about 600 $\mathrm{s}$. The operating pressure of the sprinkler was set to $0.05,0.075$ or $0.1 \mathrm{MPa}$.

The heat release rate of the pool fire was measured by six fulcrum piezoelectric weighing platforms. These platforms measure the pressure changes, with the signal digitized by the data acquisition system and stored on a PC, providing records of fuel consumption as a function of time. By differentiating this signal, we calculated the instantaneous fuel mass consumption rate, and then the heat release rate of the pool fire.

Hot wire anemometer with temperature compensation was used in experiments to measure the smoke flow velocity. Scale gauge was used to measure the thickness of the smoke layer. Measurements were performed right at the opening of the sprinkler chamber. During each experiment, the smoke flow velocity and thickness were measured every $30 \mathrm{~s}$. The average values during the steady-state stage of each experiment were then deduced.

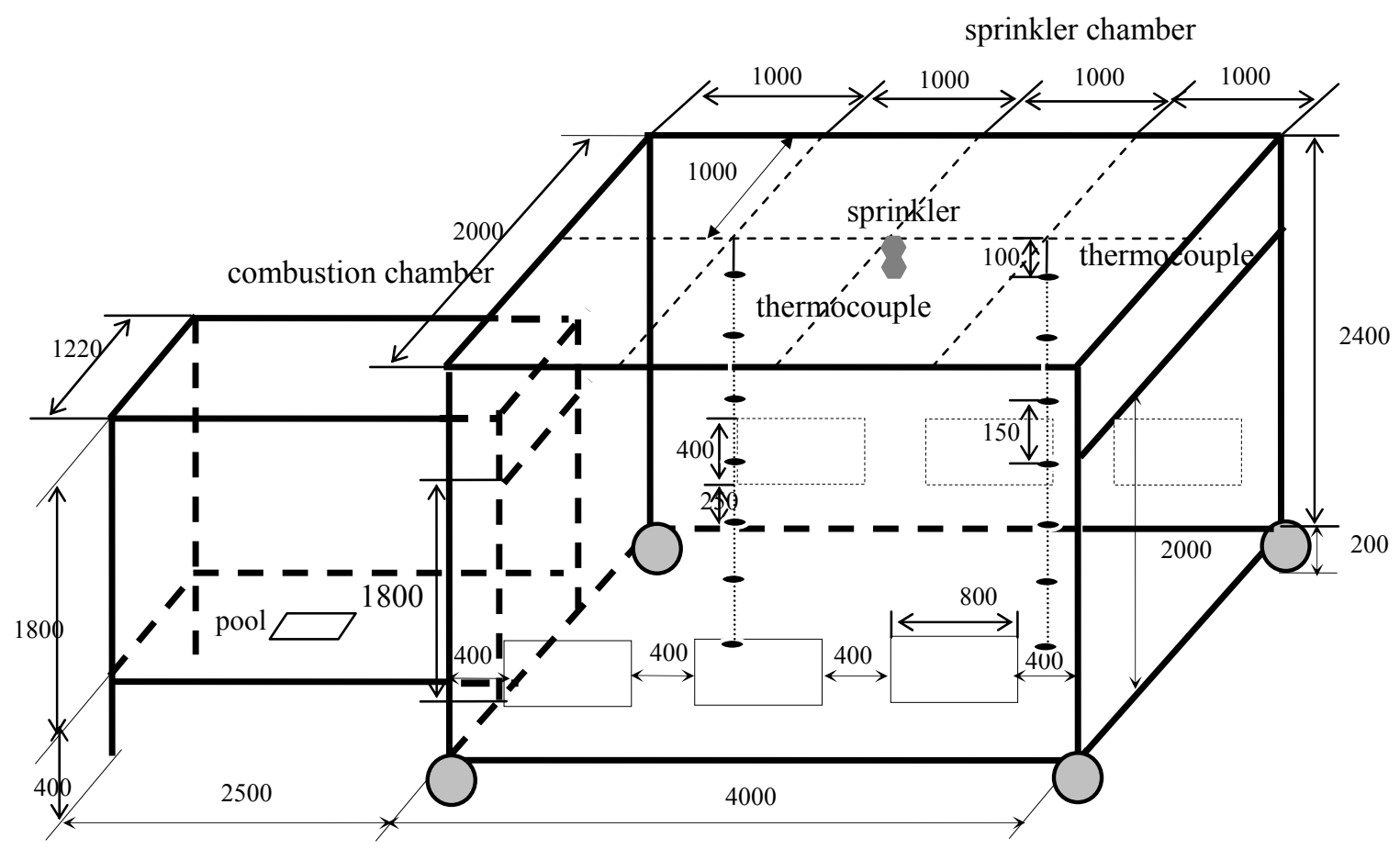

Fig. 1. Schematic diagram of the experimental rig; all dimensions are in $\mathrm{mm}$. 


\section{RESULTS AND DISCUSSION}

\section{Variations of the smoke temperature}

Based on the experimental observation, the upper eight thermocouples were located in the smoke layer, and the average temperature of the smoke layer was deduced from the readings of these thermocouples. Figures 2(a) - (d) present typical temperature histories of tests 1-16.

The average smoke temperature was estimated from the steady state portions of the temperature histories. For Figs. 2 (a), (b), (d), we estimated the smoke temperature from the measurements between 200 and 400 s, for Fig. 2 (c), between 100 and 300 s. For all conditions, the average smoke temperatures are listed in Fig. 3 .

As shown in Fig. 3, smoke temperature decreased significantly after sprinkler operation. For $0.6 \times 0.6 \mathrm{~m}$ pool fire, the average temperature rise of the smoke is $107 \mathrm{~K}$ without sprinkler; whereas the sprinkler spray, generated at $0.05 \mathrm{MPa}$, decreases this temperature rise to $35.2 \mathrm{~K}$.

When the sprinkler pressure increases, the volume medium diameter of the sprinkler spray droplets decreases and the proportion of smaller droplets increases[15], enhancing the cooling effect of the sprinkler. For $0.5 \times 0.5 \mathrm{~m}$ pool fire, and spray generated at $0.05 \mathrm{MPa}$, the average temperature rise of the smoke is 29.7 K. Likewise the average temperature rise of the smoke layer is only $20.1 \mathrm{~K}$ for the $0.1 \mathrm{MPa}$ spray.

It can be also seen from Fig. 3 that the effect of water pressure is small. For example, for $0.3 \times 0.3 \mathrm{~m}$ pool fire, and the spray pressure of $0.05 \mathrm{MPa}$, the average temperature rise of the smoke is $9.4 \mathrm{~K}$, whereas for $0.1 \mathrm{MPa}$ spray, the average temperature rise of the smoke is $4.9 \mathrm{~K}$.

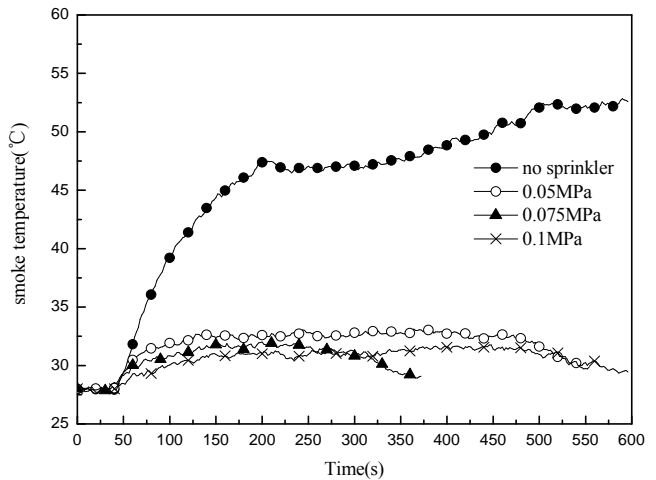

(a) $0.25 \times 0.25 \mathrm{~m}$ pool

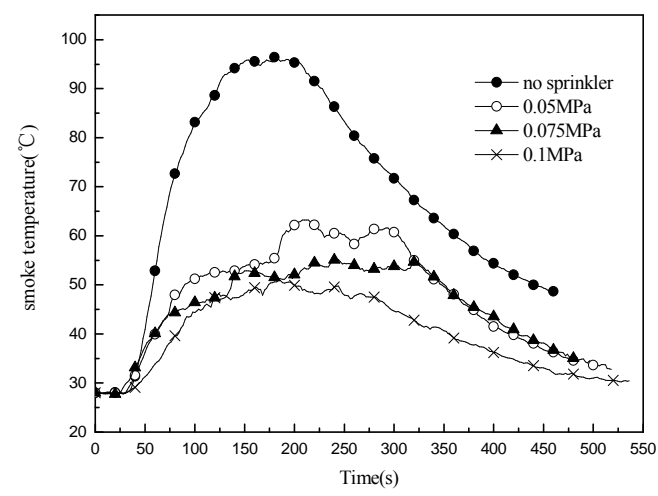

(c) $0.5 \times 0.5 \mathrm{~m}$ pool

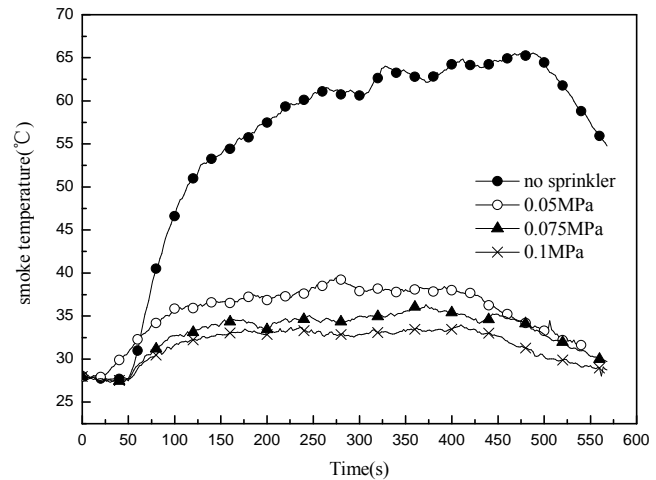

(b) $0.3 \times 0.3 \mathrm{~m}$ pool

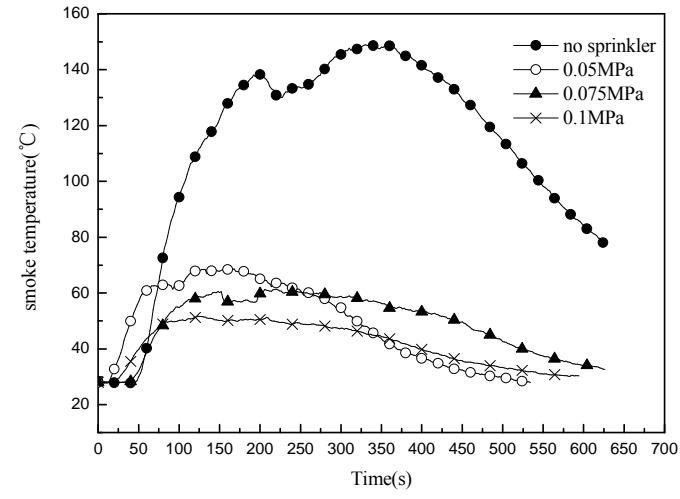

(d) $0.6 \times 0.6 \mathrm{~m}$ pool

Fig. 2. Temperature variation for different pool fires 


\section{Calculating heat loss from the smoke layer to the sprinkler spray}

The energy of the hot smoke layer before sprinkler operation can be expressed as:

$Q_{1}=m_{p} c_{p s} \Delta T=\rho_{s} V_{s} c_{p s} \Delta T=\rho_{s} U_{s} S c_{p s} \Delta T=\rho_{s} U_{s}(H-h) W c_{p s} \Delta T$

where $Q_{I}$ is the energy of smoke before sprinkler operation, $m_{p}$ mass production rate of smoke, $c_{p s}$ is specific heat of smoke, $\rho_{s}$ is density of smoke, $\Delta T$ is temperature difference between smoke and ambient air, $U_{s}$ is smoke velocity that pass through the sprinkler chamber, $S$ is smoke circulation area that pass through the sprinkler chamber, $W$ is width of the sprinkler chamber, $H$ is height of the sprinkler chamber, $h$ is the height between smoke layer to the ground.

The energy of the hot smoke layer after sprinkler operation is:

$Q_{2}=m_{p} c_{p s 2} \Delta T_{2}=\rho_{s} U_{s}(H-h) W c_{p s 2} \Delta T_{2}$

where $Q_{2}$ is the energy of smoke after sprinkler operation, $c_{p s 2}$ is the specific heat of the smoke after sprinkler operation, $\Delta T_{2}$ is temperature difference between smoke and ambient air after sprinkler operation.

The heat loss from the smoke layer to the sprinkler spray can then be deduced from the experimentally measured temperature of the smoke layer according to:

$Q=Q_{1}-Q_{2}$

where $Q$ is the experimental value for heat loss from the smoke layer to the sprinkler spray.

\section{Comparison of analytical and experimental results}

The main experimental results are summarized in Table 1, demonstrating good agreement between the measurements and the calculations, which use the values of the parameters listed in Table 2.

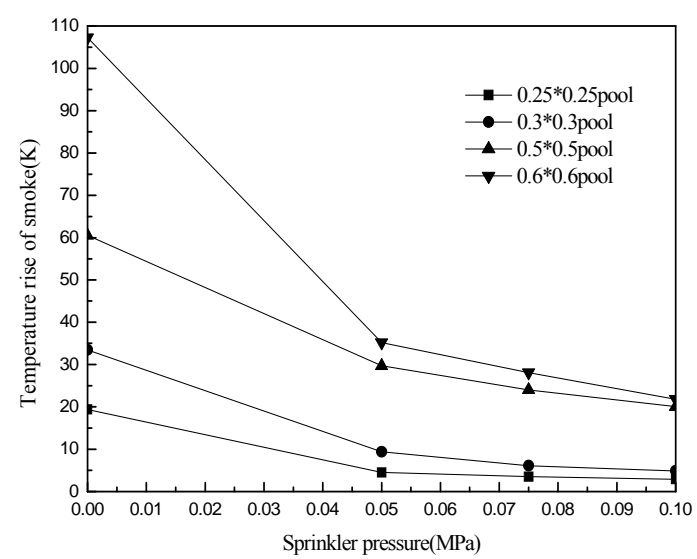

Fig. 3. Temperature rise of smoke layer versus sprinkler pressure

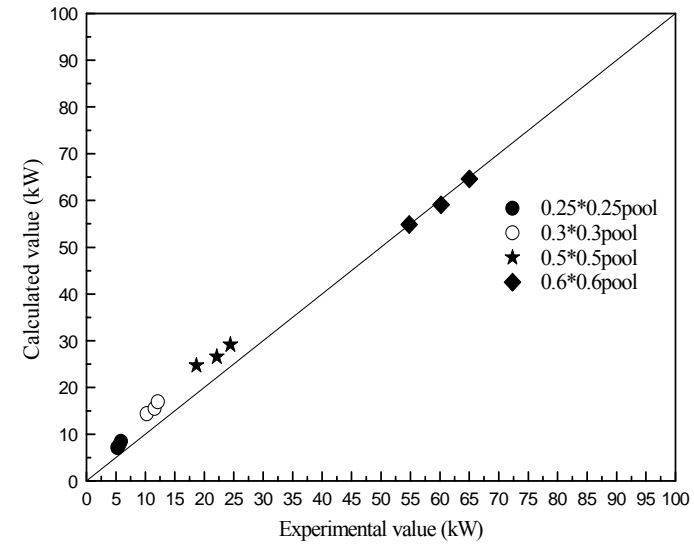

Fig. 4. Comparison of experimental and calculated smoke layer cooling 
Figure 4 compares the cooling of the smoke layer calculated by Eq. 1-20 with that measured experimentally. It can be seen that the sprinkler cooling increases to some extent with the operating pressure of the sprinkler. For smaller fires, the heat losses of the smoke layer predicted by the mathematical model slightly exceed the experimental measurements. The biggest error is $46 \%$ for test 8 , but for larger fires, the value obtained by the mathematical model agrees fairly well with the experimental data. For the $0.6 \times 0.6 \mathrm{~m}$ pool fire, for the spray generated at $0.05 \mathrm{MPa}$, experimental value of the heat extracted by the spray is $54.8 \mathrm{~kW}$ and the model value is $54.9 \mathrm{~kW}$.

\section{CONCLUSIONS}

We have developed a new model to calculate the heat loss from a smoke layer to a sprinkler spray. Our model is based on the theoretical analysis of Chow and Tang, applies a log-normal droplet-size distribution, function and neglects droplet boiling. A series of experiments was also conducted to verify the model. Results show that experimental measurements and calculated predictions are in good agreement. Sprinkler operation has a great effect on the smoke temperature. For the range of pressure studied in the present investigation, we found only a small effect of pressure on the cooling of the hot layer, consistent with the square root dependence of droplet diameter on pressure.

The model requires further improvement. Especially, one needs to incorporate the evaporation effect. Should this effect be included, the cooling would be more than that predicted in this study. Also, the droplet size distribution function and some parameters, derived from previous studies, need to be refined. A follow-up investigation is in progress and further results will be reported in a subsequent publication.

\section{ACKNOWLEDGEMENT}

This work was supported by the National Key Technology R\&D Program of China under Grant No. 2006BAK06B02.

Table 1. Summary of the tests

\begin{tabular}{|c|c|c|c|c|c|c|c|c|c|}
\hline $\begin{array}{l}\text { Test } \\
\text { No. }\end{array}$ & $\begin{array}{c}\text { Ambient } \\
\text { temperature } \\
(\mathrm{K})\end{array}$ & $\begin{array}{c}\text { Pool size } \\
\left(\mathbf{m}^{2}\right)\end{array}$ & $\begin{array}{c}\text { Heat } \\
\text { release } \\
\text { rate } \\
(\mathbf{k W})\end{array}$ & $\begin{array}{c}\text { Sprinkler } \\
\text { operating } \\
\text { pressure } \\
\text { (MPa) }\end{array}$ & $\begin{array}{l}\text { Height } \\
\text { of } \\
\text { smoke } \\
\text { layer } \\
(\mathbf{m})\end{array}$ & $\begin{array}{c}\text { Smoke } \\
\text { velocity } \\
(\mathrm{m} / \mathrm{s})\end{array}$ & $\begin{array}{l}\text { Average } \\
\text { temperature } \\
\text { rise of the } \\
\text { smoke layer } \\
\text { (K) }\end{array}$ & $\begin{array}{l}\text { Mass } \\
\text { rate of } \\
\text { smoke } \\
(\mathrm{kg} / \mathrm{s})\end{array}$ & $\begin{array}{c}\text { Experimental } \\
\text { value of } \\
\text { sprinkler } \\
\text { cooling } \\
(\mathbf{k W})\end{array}$ \\
\hline Test1 & 301 & $0.25 * 0.25$ & 52.5 & - & 1.6 & 0.36 & 19.4 & 0.35 & - \\
\hline Test2 & 301 & $0.25 * 0.25$ & 52.5 & 0.05 & 1.6 & 0.36 & 4.5 & 0.35 & 5.25 \\
\hline Test3 & 301 & $0.25 * 0.25$ & 52.5 & 0.075 & 1.6 & 0.36 & 3.5 & 0.35 & 5.6 \\
\hline Test4 & 301 & $0.25 * 0.25$ & 52.5 & 0.1 & 1.6 & 0.36 & 2.9 & 0.35 & 5.83 \\
\hline Test5 & 301 & $0.3 * 0.3$ & 72 & - & 1.55 & 0.45 & 33.5 & 0.42 & - \\
\hline Test6 & 301 & $0.3 * 0.3$ & 72 & 0.05 & 1.55 & 0.45 & 9.4 & 0.42 & 10.22 \\
\hline Test7 & 301 & $0.3 * 0.3$ & 72 & 0.075 & 1.55 & 0.45 & 6.1 & 0.42 & 11.59 \\
\hline Test8 & 301 & $0.3 * 0.3$ & 72 & 0.1 & 1.55 & 0.45 & 4.9 & 0.42 & 12.13 \\
\hline Test9 & 301 & $0.5 * 0.5$ & 145 & - & 1.5 & 0.67 & 60.5 & 0.6 & - \\
\hline Test 10 & 301 & $0.5 * 0.5$ & 145 & 0.05 & 1.5 & 0.67 & 29.7 & 0.6 & 18.67 \\
\hline Test11 & 301 & $0.5 * 0.5$ & 145 & 0.075 & 1.5 & 0.67 & 24.0 & 0.6 & 22.15 \\
\hline Test12 & 301 & $0.5 * 0.5$ & 145 & 0.1 & 1.5 & 0.67 & 20.1 & 0.6 & 24.46 \\
\hline Test13 & 301 & $0.6 * 0.6$ & 228 & - & 1.4 & 0.75 & 107 & 0.75 & - \\
\hline Test14 & 301 & $0.6 * 0.6$ & 228 & 0.05 & 1.4 & 0.75 & 35.2 & 0.75 & 54.8 \\
\hline Test15 & 301 & $0.6 * 0.6$ & 228 & 0.075 & 1.4 & 0.75 & 28.1 & 0.75 & 60.2 \\
\hline Test16 & 301 & $0.6 * 0.6$ & 228 & 0.1 & 1.4 & 0.75 & 21.8 & 0.75 & 65.02 \\
\hline
\end{tabular}




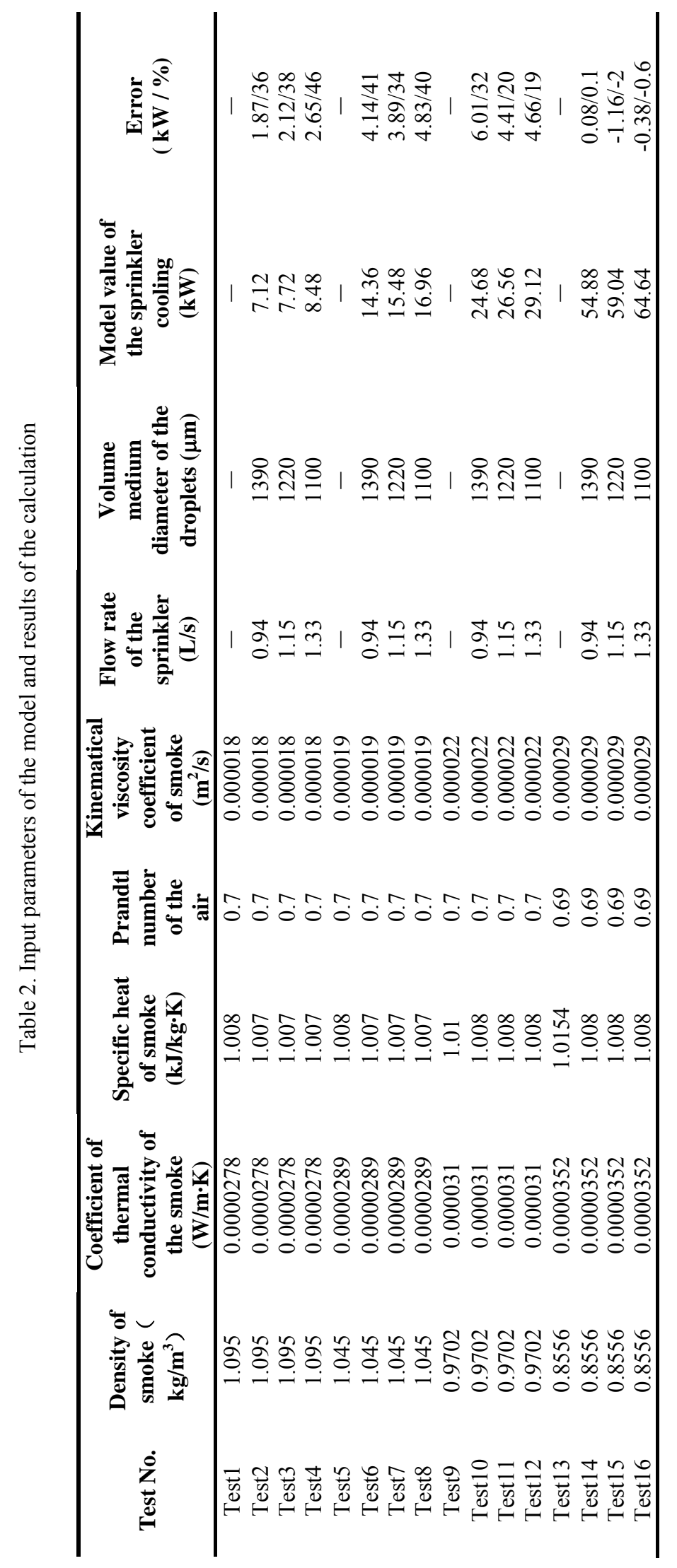




\section{REFERENCES}

[1] D.J. Rasbash, Z.W. Rogowski and S.W.V. Stark.,(1960) Mechanism of Extinction of Liquid Fires with Water Vessel, Combustion and Flame 4:223-234.

[2] D.J. Rasbash., "Heat Transfer between Water Sprays and Flames of Freely Burning Fires," Proceeding of the Symposium- the Interaction between Fluids and Particles, International Chemical Engineering, 1962,pp.218-223.

[3] Howard P. Morgan., (1979) Heat transfer From a Buoyant Smoke Layer Beneath a Ceiling to a Sprinkler Spray 1-A Tentative Theory, Fire and Materials 3: 34-38. doi:10.1002/fam.810030107

[4] Howard P. Morgan and K. Baines.,(1979) Heat transfer From a Buoyant Smoke Layer Beneath a Ceiling to a Sprinkler Spray 2 - An Experiment, Fire and Materials 3: 27-33. doi:10.1002/fam.810030106.

[5] L.Y. Cooper.,(1995) The Interaction of an Isolated Sprinkler Spray and a Two-Layer Compartment Fire Environment. Phenomena and Model Simulations, Fire Safety Journal 25:89-107. doi:10.1016/0379-7112(95)00037-2.

[6] L.Y. Cooper.,(1995) The Interaction of an Isolated Sprinkler Spray and a Two-Layer Compartment Fire Environment, International Journal Heat and Mass Transfer 38: 679-690. doi:10.1016/00179310(94)00188-2.

[7] Alpert R L.,(1985) Numerical modeling of the interaction between automatic sprinkler sprays, Fire Safety Journal 9: 157-163. doi:10.1016/0379-7112(85)90003-7.

[8] Hoffmann N F, Galea E R, Markatos N C.,(1989) Mathematical Modeling of the Fire Sprinkler Systems, Applied Mathematical Modeling 13: 298-306.

[9] Gardiner A J., The Mathematical Modeling of the Interaction Between Sprinkler Sprays and the Thermally Buoyant Layers of the Gas from Fires. PhD dissertation, South Bank Polytechnic, London, United Kingdom, 1989.

[10] Chow W K, Fong N K.,(1991) Numerical Simulation on Cooling of the Fire-induced Air Flow by Sprinkler Water Spray, Fire safety Journal 17: 263-290. doi:10.1016/0379-7112(91)90023-R.

[11] Chow W K, Fong N K.,(1993) Numerical Studies on the Interaction of Sprinklers and the Hot Layer,Architectural Science review 36: 103-111.

[12] Chow W K, Cheung Y L.,(1994) Simulation of Sprinkler-hot Layer Interaction Using a Field Model. Fire and Material, 18: 359-379. doi:10.1002/fam.810180604

[13] W.K.Chow and Anderson C.Tang.,(1994) Experimental Studies on Sprinkler Water Spray-Smoke Layer Interaction, Journal of Applied Fire Science 4: 171-184.

[14] Subramaniam S.,(2001) Statistical Modeling of Sprays Using the Droplet Distribution Function, Physics of Fluids13.

[15] J.M.Prahl and B. Wendt.,(1988) Discharge Distribution Performance for an Axisymmetric Model of a Fire Sprinkler Head, Fire Safety Journal 14: 101-111. doi:10.1016/0379-7112(88)90048-3

[16] Yu H Z., "Investigation of Spray Patterns of Selected Sprinklers with the FMRC Drop Size Measuring System," Fire Safety Science - Proceedings of the First International Symposium, International Association For Fire Safety Science, 1986, pp. 1165-1176.

[17] Chan T S.,(1994) Measurement of Water Density and Droplet Size Distributions of Selected ESFR Sprinklers, Journal of Fire Protection Engineering 6: 79-87. doi:10.1177/104239159400600202

[18] M.L.Bullen., "The Effect of a Sprinkler on the Stability of a Smoke Layer Beneath a Ceiling," Fire Research Note 1016, Fire Research Station, Borehamwood, United Kingdom,1974.

[19] Code of design for sprinkler systems, China planning press, Beijing, 2001, p.12. 